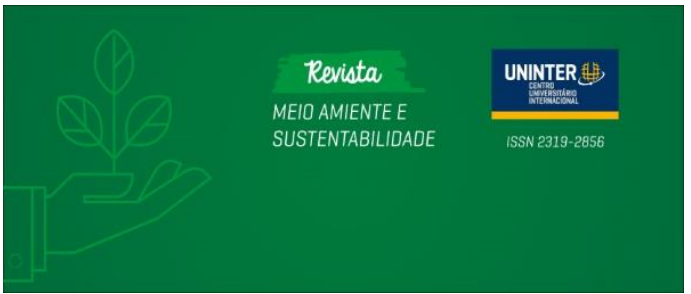

Revista Meio Ambiente e Sustentabilidade

Versão on-line ISSN 2319-2856

Volume 17, número 8. Curitiba - PR. jul/dez - 2019

\title{
Análise de práticas sustentáveis em empresas que utilizam relatório Global Reporting Iniciative (GRI)
}

Fernanda Gewehr Corrêa Gewehr

Gestora Ambiental, formada pela UNIPAMPA.

Ana Julia Senna Sarmento Barata

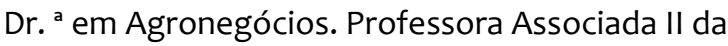
Unipampa.

Ricardo Ribeiro Alves

Professor Associado Universidade Federal do Pampa

\section{RESUMO}

No final do século XX a problemática ambiental intensificou as discussões sobre a sustentabilidade e sua importância no contexto das organizações. Com isso, as organizações passaram a ser pressionadas pelos governos e pela sociedade para que realizassem esforços para minimizar os impactos negativos causados por seus processos produtivos, visando à utilização racional dos recursos naturais, proporcionando o bem-estar dos stakeholders e a preservação do meio ambiente. Os Relatórios de Sustentabilidade são ferramentas que servem para comunicar à sociedade as ações socioambientais desenvolvidas pelas empresas. A Global Reporting Initiative (GRI) apresenta um modelo de relatório com princípios e indicadores que servem para orientar as organizações na avaliação de seu desempenho socioambiental e que possibilitam a padronização e a comparação das informações. Este trabalho tem como objetivo analisar as ações de sustentabilidade e responsabilidade social e os indicadores econômicos, ambientais e sociais que são considerados prioridade pelas empresas que utilizam o Relatório GRI versão G3.1. Foram entrevistadas cinco empresas privadas localizadas no estado do Rio Grande do Sul, que atuam nos setores da construção civil: gás liquefeito de petróleo (GLP), celulose e papel. Conclui-se que o relatório GRI é uma ferramenta que permite mensurar e economizar recursos, ademais de auxiliar na melhoria continua dos processos. Além disso, possibilita o reconhecimento e credibilidade das empresas perante os clientes e investidores.

Palavras-chave: Sustentabilidade; Desempenho Socioambiental; Global Reporting Initiative 


\title{
Analysis of sustainable pratices in companies using the Global Reporting Iniciative (GRI)
}

\author{
Análisis de prácticas sostenibles en empresas que utilizan la Global Reporting \\ Iniciative (GRI)
}

\begin{abstract}
In the end of the 2oth century, environmental issues intensified the discussions about sustainability and its importance in the context of organizations. Because of that, organizations began to be pushed by the governments and society so that they would make an effort to minimize negative environmental impacts caused by their production processes, aiming at the rational use of natural resources, providing the welfare of stakeholders and environment preservation. The Sustainability Reports are tools used to communicate society about the socio-environmental actions developed by companies. Global Report Initiative (GRI) presents a report model with principles and indicators that are used to guide the organizations on the evaluation of their socio-environmental performances and enable the standardization and the comparison of information. This paper intends to analyze the sustainability and social responsibility actions and the social, environmental and economic indicators that are considered as a priority by companies that use the G3.1 version of the GRI report. Five companies localized in the state of Rio Grande do Sul were interviewed. They work in civil construction sectors: LPG gas, cellulose and paper. It was concluded that the GRI report is a tool that allows measuring and sparing the resources it has, in addition to help the continuous improvement of the processes. Moreover, it allows the recognition and credibility of the companies towards their clients and investors.
\end{abstract}

Keywords: Sustainability; Socio-environmental Performance; Global Reporting Initiative

\section{RESUMEN}

Al final del siglo XX la problemática ambiental intensificó las discusiones sobre la sustentabilidad y su importancia en el contexto de las organizaciones. Con eso, las organizaciones empezaron a ser presionadas por los gobiernos y por la sociedad en el sentido de realizar esfuerzos para minimizar los impactos negativos causados por sus procesos productivos, para utilizar racionalmente los recursos naturales, garantizar el bienestar de los stakeholders y la preservación del medio ambiente. Los Informes de Sostenibilidad son herramientas que sirven para comunicar a la sociedad las acciones socioambientales desarrolladas por las empresas. La Global Reporting Iniciative (GRI) presenta un modelo de informe con principios e indicadores que sirven para orientar a las organizaciones en la evaluación de su desempeño socioambiental; permiten también la unificación y comparación de las informaciones. Este trabajo tiene el objetivo de analizar las acciones de sostenibilidad y responsabilidad social y los indicadores económicos, ambientales y sociales considerados como prioridad por las empresas que utilizan la GRI versión G3.1. Se entrevistaron cinco empresas privadas, ubicadas en el estado de Rio Grande do Sul (Brasil), que actúan en los sectores de la construcción civil: gas licuado de petróleo (GLP), celulosa y papel. Se concluye que el reporte GRI es una herramienta que permite medir y ahorrar recursos, además de aportar mejoras continuas en los procesos. Asimismo, garantiza el reconocimiento y credibilidade de las empresas frente a sus clientes e inversionistas.

Palabras-clave: Sustentabilidad; Desempeño socioambiental; Global Reporting Initiative

\section{INTRODUÇÃO}

Inicialmente marcada como uma revolução tecnológica com a descoberta da máquina a vapor, a Revolução Industrial teve como consequência outras transformações no âmbito econômico, social, político e ambiental. (VEIGA, 2005). 
Hoje, conforme Boff (2012), a problemática ambiental incide em uma pressão sobre os governos e empresas para que realizem esforços na busca de um desenvolvimento mais sustentável. A conscientização das empresas e seus gestores em entender e aceitar que possuem obrigações sociais e precisam adotar posturas mais proativas, é consequência do aumento do rigor legal, da demanda da sociedade por maior transparência e pelas pressões competitivas (OLIVEIRA et al., 2013).

A GRI (Global Reporting Initiative) é uma iniciativa voluntária da Ceres e do Tellus Institute com apoio do Programa das Nações Unidas para o Meio Ambiente (PNUMA), que dispõe de princípios e indicadores para uma elaboração padronizada de relatórios de sustentabilidade, abrangendo o desempenho econômico, ambiental e social. Possibilita que diferentes organizações, independentemente de seu porte ou setor de atuação, possam relatar suas ações (ALMEIDA, 2012).

\section{OBJETIVOS}

Diante da pressão para relatar as informações socioambientais, as organizações têm elaborado ações responsáveis em relação aos impactos gerados no meio ambiente por seus processos de produção. Assim, esse trabalho tem como objetivo analisar as ações de sustentabilidade e os indicadores econômicos, ambientais e sociais da matriz GRI que são considerados prioridade pelas empresas que utilizam o Relatório Global Reporting Initiative, versão G3.1.

\section{REFERENCIAL TEÓRICO}

\section{Global Reporting Initiative - GRI}

Após a Conferência da Rio-92, a Agenda 21 reconheceu a necessidade de estimular o setor privado a divulgar periodicamente relatórios ambientais com detalhamento do uso de energia e dos recursos naturais. Com esse intuito, nasceu a Global Reporting Initiative (GRI) uma organização sem fins lucrativos, com sede na Holanda e constituída por especialistas de diversos países. A GRI tem como objetivo melhorar a qualidade e a aplicabilidade dos relatórios de sustentabilidade, pois os modelos 
existentes não forneciam dados sobre as dimensões econômicas, sociais e ambientais (ALMEIDA, 2012; QUELHAS et al., 2013).

A GRI é representada por quatro gerações de relatórios. Segundo Quelhas et al. (2013), a evolução é reflexo do grau de interesse, de complexas estruturas sociais, econômicas e políticas que incentivam a integração da sustentabilidade à estratégia organizacional.

A primeira geração de diretrizes GRI (G1) foi publicada no ano de 1999. Em 2002, houve a publicação da segunda geração (G2), mas as necessidades de aprimorar as diretrizes fizeram com que não muito tempo depois, no ano de 2006 publicassem a terceira geração (G3). No ano de 2011 ocorreu a revisão da terceira geração (G3.1), acrescentando ao relatório indicadores a fim de avaliar a performance dos impactos aos direitos humanos, comunidade local e de gênero. A última geração de suas diretrizes G4, foi lançada em 2013, com o intuito de melhorar a qualidade técnica, a uniformidade e aumentar a facilidade de uso (QUELHAS et al., 2013; GRI, 2011).

O GRI é uma ferramenta que auxilia as organizações a relatarem suas práticas socioambientais, tendo como objetivo ajudar a organização a mensurar seu desempenho ambiental, social e econômico, aumentando a sua credibilidade no mercado. A relevância do tema abordado está na necessidade de avaliar as informações prestadas nos relatórios de sustentabilidade, bem como verificar a eficácia dessas informações (SAVITZ e WEBER, 2007; Quelhas et al, 2013).

De acordo com Quelhas et al. (2013) a elaboração de relatórios que seguem as diretrizes GRI, apoiam a comunicação fortalecendo o diálogo e a confiança das partes interessadas. É considerada uma ferramenta de gestão, pois permite visualizar problemas que se repetem, auxiliando o gerenciamento de riscos nas operações. Também auxilia na gestão da reputação da marca e na aproximação com investidores, ao identificar oportunidades na cadeia produtiva.

\section{Estrutura para Elaboração do Relatório Global Reporting Initiative}

Considerando que as empresas respondentes elaboraram o relatório de sustentabilidade com base na versão 3.1 da GRI, serão consideradas para efeito de referencial teórico da estrutura do Relatório Global Reporting Initiative, as diretrizes G3. 
Através do relatório GRI, as organizações são postas em um um mesmo nível - o que auxilia na análise e comparação do desempenho socioambiental. Elaborada por meio de um processo chamado "processo multistakeholder", utilizado para produzir as Diretrizes da GRI, os Protocolos de Indicadores e os Suplementos Setoriais (ALMEIDA, 2012; QUELHAS et al., 2013).

A Figura 1, ilustra os três elementos principais do processo de elaboração do relatório

Figura 1 - Opções para elaborar o Relatório GRI

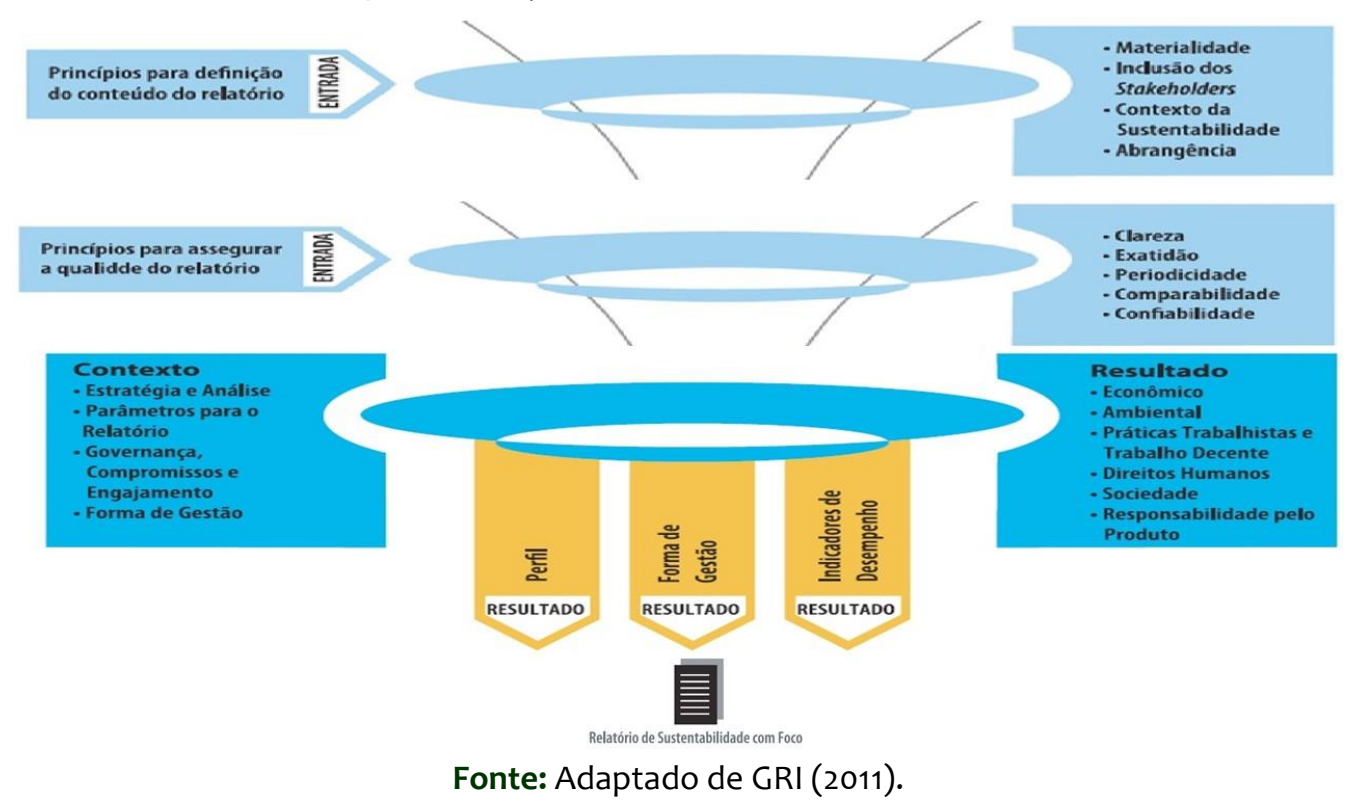

O primeiro elemento da Figura 1 compreende os princípios para definição do conteúdo do relatório. Compreende os seguintes aspectos:

- Materialidade: impactos econômicos, ambientais e sociais significativos da organização.

- Inclusão dos Stakeholders: consiste na identificação dos stakeholders e expor as medidas em resposta aos seus interesses e expectativas;

- Contexto da Sustentabilidade: Desempenho da organização;

- Abrangência: A cobertura dos temas e indicadores relevantes. Deverá ser suficiente para refletir os impactos econômicos, ambientais e sociais significativos e permitir que os stakeholders avaliem o desempenho da organização no período analisado.

O segundo elemento da Figura 1, apresenta princípios que orientam escolhas para assegurar a qualidade das informações relatadas. Consistem em:

- Clareza: Informações compreensíveis e acessíveis aos stakeholders. 
- Exatidão: Informações detalhadas para que os stakeholders avaliem o desempenho da organização relatora.

- Periodicidade: O relatório deve ser publicado regularmente e as informações são disponibilizadas a tempo para que os stakeholders tomem decisões fundamentadas.

- Comparabilidade: As informações deverão ser relatadas de modo que permita aos stakeholders analisar mudanças no desempenho da organização ao longo do tempo e subsidiar análises sobre outras organizações.

- Confiabilidade: As informações e processos usados na preparação do relatório deverão ser coletados, registrados, compilados, analisados e divulgados de uma forma que permita sua revisão e estabeleça a qualidade e materialidade das informações.

O terceiro e último elemento compreende o conteúdo básico que deverá constar em um relatório de sustentabilidade. Há três tipos de conteúdo:

- Perfil: Informações necessárias para compreensão do desempenho organizacional, incluindo sua estratégia, perfil e governança;

- Forma de Gestão: Explicitar o contexto no qual deve ser interpretado o desempenho da organização em uma área específica;

- Indicadores de Desempenho: Expõe informações sobre o desempenho econômico, ambiental e social da organização passíveis de comparação.

Os indicadores da GRI, definem os princípios para auxiliar as organizações a mensurar e relatar o seu desempenho econômico, ambiental e social. São divididos entre os essenciais, aqueles considerados relevantes e identificados como prioridade dos stakeholders, e os adicionais, aqueles que relatam práticas emergentes e são opcionais (MONEVA; ARCHEL; CORREA, 2006).

O Quadro 1 apresenta um resumo dos conteúdos padrão gerais. Os mesmos aplicamse a todas as organizações que elaboram relatórios de sustentabilidade e dividem-se em sete partes.

Quadro 1 - Resumo dos conteúdos padrão gerais

\begin{tabular}{|c|c|c|}
\hline $\begin{array}{c}\text { Conteúdos Padrões } \\
\text { Gerais }\end{array}$ & Aspecto & Indicadores \\
\hline Estratégia e análise & $\begin{array}{c}\text { Visão estratégica geral da } \\
\text { sustentabilidade da organização }\end{array}$ & G3-1 e G3-2 \\
\hline
\end{tabular}




\begin{tabular}{|c|c|c|}
\hline $\begin{array}{c}\text { Perfil } \\
\text { organizacional }\end{array}$ & $\begin{array}{c}\text { Visão geral das características } \\
\text { organizacionais }\end{array}$ & G3-3 ao G3-16 \\
\hline $\begin{array}{c}\text { Aspectos materiais } \\
\text { identificados e } \\
\text { limite }\end{array}$ & $\begin{array}{c}\text { Visão geral do processo adotado pela } \\
\text { organização para definir o conteúdo do } \\
\text { relatório,Aspectos materiais identificados } \\
\text { e seus limites e reformulações. }\end{array}$ & G3-17 ao G3-23 \\
\hline $\begin{array}{c}\text { Engajamento de } \\
\text { stakeholders }\end{array}$ & $\begin{array}{c}\text { Visão geral do engajamento de } \\
\text { stakeholders da organização no decorrer } \\
\text { do período coberto pelo relatório. }\end{array}$ & G3-24 ao G3-27 \\
\hline Perfil do relatório & $\begin{array}{c}\text { Visão geral de informações básicas sobre } \\
\text { o relatório, o Sumário de Conteúdo da GRI } \\
\text { e a abordagem adotada para garantir a } \\
\text { verificação externa. }\end{array}$ & G3-28 ao G3-33 \\
\hline Governança & $\begin{array}{c}\text { Visão geral sobre a estrutura de } \\
\text { governança e sua composição }\end{array}$ & G3-34 ao G3-55 \\
\hline Ética e integridade & $\begin{array}{c}\text { Visão geral sobre os valores, princípios, } \\
\text { padrões e normas da organização. }\end{array}$ & G3-56, G3-57, G3-58 \\
\hline
\end{tabular}

Fonte: GRI, 2011.

O Quadro 2, apresenta o resumo dos conteúdos padrão específicos a serem relatados em três categorias econômica, ambiental e social que se divide em quatro subcategorias.

\begin{tabular}{|c|c|c|c|c|}
\hline \multirow{2}{*}{\multicolumn{2}{|c|}{ Categoria }} & \multirow{2}{*}{ Aspecto } & \multicolumn{2}{|c|}{ Indicadores } \\
\hline & & & Essencial & Adicional \\
\hline \multirow{3}{*}{\multicolumn{2}{|c|}{ Econômica }} & $\begin{array}{c}\text { Desempenho } \\
\text { econômico }\end{array}$ & $\begin{array}{c}E C_{1}, E C 2, E C_{3}, \\
E C 4\end{array}$ & N/A \\
\hline & & Presença no mercado & $\mathrm{EC6}, \mathrm{EC7}$ & EC5 \\
\hline & & $\begin{array}{c}\text { Impactos econômicos } \\
\text { indiretos }\end{array}$ & EC8 & EC9 \\
\hline \multirow{9}{*}{\multicolumn{2}{|c|}{ Ambiental }} & Materiais & $\mathrm{EN} 1, \mathrm{EN}_{2}$ & $\mathrm{~N} / \mathrm{A}$ \\
\hline & & Energia & $\mathrm{EN}_{3}, \mathrm{EN}_{4}$ & $\begin{array}{l}\text { EN5, EN6, } \\
\text { EN7 }\end{array}$ \\
\hline & & Água & EN8 & EN9, EN10 \\
\hline & & Biodiversidade & EN11, EN12, & $\begin{array}{c}\text { EN13, EN14. } \\
\text { EN15 }\end{array}$ \\
\hline & & $\begin{array}{l}\text { Emissões, Efluentes e } \\
\text { resíduos }\end{array}$ & $\begin{array}{c}\text { EN16, EN17, } \\
\text { EN19, EN20, } \\
\text { EN21, EN22, } \\
\text { EN23 }\end{array}$ & $\begin{array}{c}\text { EN18, } \\
\text { EN24, EN25 }\end{array}$ \\
\hline & & Produtos e serviços & EN26, EN27 & $N \backslash A$ \\
\hline & & Conformidade & EN28 & $\mathrm{N} / \mathrm{A}$ \\
\hline & & Transporte & $\mathrm{N} / \mathrm{A}$ & EN29 \\
\hline & & Geral & $\mathrm{N} / \mathrm{A}$ & EN30 \\
\hline \multirow{2}{*}{ Social } & \multirow{2}{*}{ Práticas trabalhistas } & Emprego & $L_{1} 1, L A 2, L A 3$ & LA4 \\
\hline & & Relações trabalhistas & LA5, LA6, & N/A \\
\hline
\end{tabular}




\begin{tabular}{|c|c|c|c|}
\hline & $\begin{array}{c}\text { Saúde e segurança no } \\
\text { trabalho }\end{array}$ & LA7, LA8 & LA9, LA10 \\
\hline & $\begin{array}{c}\text { Treinamento e } \\
\text { educação }\end{array}$ & LA11 & LA12, LA13 \\
\hline & $\begin{array}{l}\text { Diversidade e igualdade } \\
\text { de oportunidades }\end{array}$ & LA14 & \\
\hline & $\begin{array}{c}\text { Igual remuneração para } \\
\text { mulheres e homens }\end{array}$ & LA15 & \\
\hline & $\begin{array}{c}\text { Práticas de } \\
\text { investimentos e } \\
\text { processos de compra }\end{array}$ & $\mathrm{HR} 1, \mathrm{HR} 2$ & $\mathrm{HR}_{3}$ \\
\hline & Não discriminação & HR4 & $\mathrm{N} / \mathrm{A}$ \\
\hline & $\begin{array}{c}\text { Liberdade de associação } \\
\text { e negociação coletiva }\end{array}$ & $\mathrm{HR}_{5}$ & $N / A$ \\
\hline Direitos humanos & Trabalho infantil & HR6 & $\mathrm{N} / \mathrm{A}$ \\
\hline & $\begin{array}{l}\text { Trabalho forçado ou } \\
\text { análogo ao escravo }\end{array}$ & $\mathrm{HR} 7$ & $N / A$ \\
\hline & Práticas de segurança & $\mathrm{N} / \mathrm{A}$ & HR8 \\
\hline & Direitos indígenas & $\mathrm{N} / \mathrm{A}$ & HR9 \\
\hline & Avaliação & HR10 & \\
\hline & Remediação & HR11 & \\
\hline & Comunidades & $\mathrm{SO} 1$ & SO9, SO10 \\
\hline & Combate a corrupção & $\mathrm{SO}_{2}, \mathrm{SO}_{3}, \mathrm{SO}_{4}$ & $\mathrm{~N} / \mathrm{A}$ \\
\hline Sociedade & Políticas públicas & $\mathrm{SO}_{5}$ & SO6 \\
\hline & Concorrência desleal & $\mathrm{N} / \mathrm{A}$ & $\mathrm{SO} 7$ \\
\hline & Conformidade & $\mathrm{SO} 8$ & $\mathrm{~N} / \mathrm{A}$ \\
\hline & $\begin{array}{c}\text { Saúde e segurança do } \\
\text { cliente }\end{array}$ & PR1 & PR2 \\
\hline Responsabilidade & $\begin{array}{c}\text { Rotulagem de produtos } \\
\text { e serviços }\end{array}$ & PR3 & $\mathrm{PR}_{4}, \mathrm{PR}_{5}$ \\
\hline pelo produto & $\begin{array}{c}\text { Comunicação de } \\
\text { marketing }\end{array}$ & PR6 & PR7 \\
\hline & Privacidade do cliente & $\mathrm{N} / \mathrm{A}$ & PR8 \\
\hline & Conformidade & PR9 & $\mathrm{N} / \mathrm{A}$ \\
\hline
\end{tabular}

Fonte: GRI, 2011.

O Relatório de Sustentabilidade da GRI é uma ferramenta que permite que qualquer organização, independentemente de porte ou setor de atuação, adeque o relatório à sua realidade para divulgar seu desempenho socioambiental. Além disso, é uma ferramenta que possibilita mensurar e economizar os seus recursos internos, auxiliando na melhoria contínua dos processos produtivos (GRI, 2011). 


\section{METODOLOGIA DA PESQUISA}

A presente pesquisa é caracterizada por ser uma pesquisa exploratória, pois tem a finalidade de explorar um problema ou situação para prover critérios e compreensão. A pesquisa utiliza dados primários, originados pelo pesquisador a fim de formular um problema ou defini-lo com maior precisão e dados secundários (MALHOTRA, 2001).

Foram entrevistadas cinco empresas privadas com filiais situadas no estado do Rio Grande do Sul, de diferentes setores de atuação. A seleção foi feita em função das empresas que divulgam seu Relatório de Sustentabilidade, seguindo as diretrizes da Global Reporting Initiative (GRI) versão 3.1.

Para o referencial teórico foram utilizados como fonte de coleta de dados: livros, artigos, teses, dissertações, periódicos, sites institucionais e relatórios publicados.

Realizou-se entrevistas de caráter qualitativo, afim de estimular os entrevistados a pensarem e falarem livremente sobre os temas abordados. A Figura 2, ilustra as etapas do método.

Figura 2 - Etapas do método

\begin{tabular}{l|l|}
\hline $3^{\circ}$ & Elaboração do referencial teórico \\
\hline $\begin{array}{l}\text { - Realização da pesquisa } \\
\text { - Identificação das empresas no RS; } \\
\text { - Contato via e-mail e telefone com as empresas; } \\
\text { - Agendamento prévio; }\end{array}$ \\
\hline $\begin{array}{l}\text { - Realização das entrevistas } \\
\text { - Ananscrição dos dados; } \\
\text { - Análise do do instrumento de coleta de dados; }\end{array}$ \\
\hline Fonte: Autores, 2016.
\end{tabular}

Com base no referencial teórico e nos relatórios de sustentabilidade divulgados, elaborou-se o roteiro de entrevistas, divididas em duas partes:

- I parte: Caracterização da empresa investigada; 
- II parte: Caracterização das atitudes e práticas das empresas investigadas em busca de Sustentabilidade;

A pesquisa exploratória iniciou-se via internet em sites institucionais, afim de identificar empresas situadas no estado do Rio Grande do Sul, que elaboraram e divulgaram seu Relatório de Sustentabilidade segundos as diretrizes da GRI versão 3.1, no ano de 2014.

Em seguida, foi realizado primeiro contato com nove empresas via e-mail e telefone para agendamento das entrevistas. Destas, cinco se propuseram a realizar as entrevistas e encaminharam o contato dos respondentes. Duas informaram que não teriam disponibilidade de tempo para responder e duas relataram que não se enquadravam no perfil da pesquisa. Do total de cinco entrevistas realizadas, duas foram realizadas pessoalmente e três vias telefone, em função dos colaboradores responsáveis residirem em outro estado.

Ao realizar as entrevistas, ficou acordado com as empresas, que em função do sigilo quanto a identificação das empresas incluídas na pesquisa e que, na análise, tais empresas serão codificadas como A, B, C, D e. O Quadro 3, apresenta o perfil dos entrevistados.

\begin{tabular}{|c|c|c|c|c|}
\hline Empresa & Setor & Área de atuação & $\begin{array}{c}\text { Perfil do } \\
\text { entrevistado }\end{array}$ & $\begin{array}{l}\text { Tempo de } \\
\text { atuação na } \\
\text { empresa }\end{array}$ \\
\hline A & Gás GLP & $\begin{array}{l}\text { Planejamento } \\
\text { estratégico }\end{array}$ & Relações públicas & 3 anos \\
\hline B & $\begin{array}{l}\text { Papel e } \\
\text { celulose }\end{array}$ & $\begin{array}{c}\text { Assessoria em } \\
\text { sustentabilidade }\end{array}$ & Administração & 1 ano \\
\hline C & $\begin{array}{l}\text { Construção } \\
\text { civil }\end{array}$ & $\begin{array}{c}\text { Analista de } \\
\text { Sustentabilidade } \\
\text { Regional }\end{array}$ & Gestor Ambiental & 1 ano \\
\hline D & $\begin{array}{c}\text { Construção } \\
\text { civil }\end{array}$ & Engenheiro Ambiental & $\begin{array}{c}\text { Engenharia } \\
\text { Ambiental } \\
\end{array}$ & 5 anos \\
\hline E & $\begin{array}{l}\text { Papel e } \\
\text { celulose }\end{array}$ & $\begin{array}{l}\text { Comunicação e } \\
\text { relacionamento } \\
\text { institucional }\end{array}$ & $\begin{array}{l}\text { Comunicação Social o } \\
\text { e Pós em Gestão de } \\
\text { crises }\end{array}$ & 20 anos \\
\hline
\end{tabular}

Fonte: Autores, 2016.

A última etapa da pesquisa constitui-se na transcrição e análise dos dados coletados confrontando-os com as informações dos relatórios de sustentabilidade divulgados, para melhor compreensão dos resultados. 
A matriz da GRI versão 3.1, apresenta 81 indicadores para avaliar o desempenho econômico, social e ambiental. No manual de implementação das diretrizes, direcionado aos profissionais que elaboram o relatório, a GRI tem uma legenda de letras e números para cada aspecto do GRI a ser relatado. Os códigos são uma maneira de facilitar a compreensão. O Quadro 4 apresenta os aspectos e suas legendas.

Quadro 4 - Legenda dos conteúdos padrões GRI

\begin{tabular}{|c|c|c|c|c|}
\hline \multirow{2}{*}{\multicolumn{2}{|c|}{ Categoria }} & \multirow[t]{2}{*}{ Aspecto } & \multicolumn{2}{|c|}{ Indicadores } \\
\hline & & & \begin{tabular}{|l|} 
Essencial \\
\end{tabular} & Adicional \\
\hline \multirow{3}{*}{\multicolumn{2}{|c|}{ Econômica }} & Desempenho econômico & EC1, EC2, EC3, EC4 & N/A \\
\hline & & Presença no mercado & EC6, EC7 & EC5 \\
\hline & & Impactos econômicos indiretos & EC8 & EC9 \\
\hline \multirow{9}{*}{\multicolumn{2}{|c|}{ Ambiental }} & \begin{tabular}{|c|} 
Materiais \\
\end{tabular} & EN1, EN2 & N/A \\
\hline & & Energia & EN3, EN4 & EN5, EN6, EN7 \\
\hline & & Agua & EN8 & EN9, EN10 \\
\hline & & Biodiversidade & EN11, EN12, & $\begin{array}{l}\text { EN13, EN14. } \\
\text { EN15 }\end{array}$ \\
\hline & & Emissões, Efluentes e resíduos & $\begin{array}{l}\text { EN16, EN17, } \\
\text { EN19, EN20, EN21, } \\
\text { EN22, EN23 }\end{array}$ & $\begin{array}{l}\text { EN18, EN24, } \\
\text { EN25 }\end{array}$ \\
\hline & & Produtos e serviços & EN26, EN27 & NIA \\
\hline & & Conformidade & EN28 & $\mathrm{N} / \mathrm{A}$ \\
\hline & & Transporte & $\mathrm{N} / \mathrm{A}$ & EN29 \\
\hline & & Geral & N/A & EN30 \\
\hline \multirow{6}{*}{\multicolumn{2}{|c|}{$\begin{array}{l}\text { Práticas } \\
\text { trabalhistas }\end{array}$}} & Emprego & LA1, LA2, LA3 & LA4 \\
\hline & & Relações trabalhistas & LA5, LA6, & N/A \\
\hline & & Saúde e segurança no trabalho & LA7, LA8 & LA9, LA10 \\
\hline & & Treinamento e educação & LA11 & LA12, LA13 \\
\hline & & $\begin{array}{l}\text { Diversidade e igualdade de } \\
\text { oportunidades }\end{array}$ & LA14 & \\
\hline & & $\begin{array}{l}\text { Igual remuneração para } \\
\text { mulheres e homens }\end{array}$ & LA15 & \\
\hline \multirow{19}{*}{ Social } & \multirow{9}{*}{ Direitos humanos } & $\begin{array}{c}\text { Práticas de investimentos e } \\
\text { processos de compra }\end{array}$ & HR1, HR2 & HR3 \\
\hline & & Não discriminação & HR4 & $\mathrm{N} / \mathrm{A}$ \\
\hline & & $\begin{array}{l}\text { Liberdade de associação e } \\
\text { negociação coletiva }\end{array}$ & HR5 & $\mathrm{N} / \mathrm{A}$ \\
\hline & & Trabalho infantil & HR6 & $\mathrm{N} / \mathrm{A}$ \\
\hline & & $\begin{array}{c}\text { Trabalho forçado ou análogo ao } \\
\text { escravo }\end{array}$ & HR7 & $\mathrm{N} / \mathrm{A}$ \\
\hline & & \begin{tabular}{|l|} 
Práticas de segurança \\
\end{tabular} & $\mathrm{N} / \mathrm{A}$ & HR8 \\
\hline & & Direitos indígenas & N/A & HR9 \\
\hline & & Avaliação & HR10 & \\
\hline & & Remediação & HR11 & \\
\hline & \multirow{5}{*}{ Sociedade } & Comunidades & SO1 & SO9, SO10 \\
\hline & & Combate a corrupção & $\mathrm{SO} 2, \mathrm{SO} 3, \mathrm{SO} 4$ & $\mathrm{~N} / \mathrm{A}$ \\
\hline & & Políticas públicas & SO5 & SO6 \\
\hline & & Concorrência desleal & N/A & SO7 \\
\hline & & Conformidade & SO8 & N/A \\
\hline & \multirow{5}{*}{$\begin{array}{l}\text { Responsabilidade } \\
\text { pelo produto }\end{array}$} & Saúde e segurança do cliente & PR1 & PR2 \\
\hline & & $\begin{array}{l}\text { Rotulagem de produtos e } \\
\text { serviços }\end{array}$ & PR3 & PR4, PR5 \\
\hline & & Comunicação de marketing & PR6 & PR7 \\
\hline & & Privacidade do cliente & N/A & PR8 \\
\hline & & Conformidade & PR9 & N/A \\
\hline
\end{tabular}

Fonte: GRI, 2011. 


\section{ANÁLISE DOS DADOS}

A seguir, serão descritos e analisados os resultados das entrevistas com as empresas que divulgam o Relatório GRI versão G3.1.

\section{Caracterização das Empresas}

O Quadro 5 sintetiza as principais informações sobre o perfil das empresas entrevistadas.

Quadro 5 - Caracterização das Empresas Entrevistadas

\begin{tabular}{|c|c|c|c|c|c|}
\hline Empresa & Fundação & $\begin{array}{c}\text { Setor } \\
\text { de atuação }\end{array}$ & $\begin{array}{l}\text { Origem do } \\
\text { capital }\end{array}$ & $\begin{array}{c}\mathrm{N}^{\circ} \text { de } \\
\text { funcionários }\end{array}$ & Tipo de gestão \\
\hline A & $\begin{array}{c}1955 \\
16 \text { unidades } \\
\text { distribuídas em } \\
10 \text { estados } \\
\text { brasileiros }\end{array}$ & $\begin{array}{c}\text { Engarrafa, } \\
\text { distribui e } \\
\text { transporta } \\
\text { GLP }\end{array}$ & $\begin{array}{l}\text { Capital } \\
\text { fechado }\end{array}$ & $\begin{array}{c}\text { Brasil } \\
1590 \\
\text { funcionários } \\
107 \text { no RS }\end{array}$ & Verticalizada \\
\hline B & $\begin{array}{c}1899 \\
15 \text { unidades em } \\
7 \text { estados } \\
\text { brasileiros e } 1 \\
\text { na Argentina }\end{array}$ & $\begin{array}{c}\text { Papel e } \\
\text { Celulose - } \\
\text { Embalagens }\end{array}$ & $\begin{array}{c}\text { Capital } \\
\text { aberto/ } \\
\text { capital } \\
\text { privado } \\
\text { pulverizado }\end{array}$ & $\begin{array}{c}\text { Brasil } \\
16.334 \\
\text { funcionários }\end{array}$ & Horizontalizada \\
\hline C & $\begin{array}{c}1960 \\
37 \text { unidades } \\
\text { distribuídas em } \\
8 \text { estados } \\
\text { brasileiros } \\
\text { atuam em } 7 \\
\text { países. }\end{array}$ & $\begin{array}{c}\text { Varejo de } \\
\text { materiais de } \\
\text { construção/ } \\
\text { Acabamento } \\
\text { e bricolagem }\end{array}$ & $\begin{array}{l}\text { Capital } \\
\text { fechado }\end{array}$ & $\begin{array}{c}\text { Brasil } \\
7.573 \text { mil } \\
\text { funcionários }\end{array}$ & Horizontalizada \\
\hline D & $\begin{array}{c}1951 \\
22 \text { unidades } \\
\text { distribuídas em } \\
8 \text { estados } \\
\text { brasileiros e } 4 \\
\text { na Colômbia. }\end{array}$ & $\begin{array}{l}\text { Construção } \\
\text { Civil }\end{array}$ & $\begin{array}{l}\text { Capital } \\
\text { aberto }\end{array}$ & $\begin{array}{c}\text { Brasil } \\
12.200 \\
\text { funcionários } \\
1.302 \text { no RS }\end{array}$ & Horizontalizada \\
\hline$E$ & $\begin{array}{c}1972 \\
2 \text { unidades no } \\
\text { RS e outras } 23 \\
\text { unidades } \\
\text { distribuídas em } \\
6 \text { países }\end{array}$ & $\begin{array}{l}\text { Papel e } \\
\text { Celulose }\end{array}$ & $\begin{array}{l}\text { Capital } \\
\text { fechado }\end{array}$ & $\begin{array}{c}\text { No RS } 5.000 \\
\text { funcionários } \\
\text {, entre } \\
\text { próprios e } \\
\text { prestadores } \\
\text { de serviço } \\
\text { permanente } \\
\text { s }\end{array}$ & Horizontalizada \\
\hline
\end{tabular}

Fonte: Autores, 2016. 
Conforme o Quadro 5, percebe-se que a empresa com maior tempo de mercado e maior número de funcionários é a empresa $\mathbf{B}$. Das entrevistadas, a que tem o maior número de unidades no Brasil é a empresa C, com 37 unidades distribuídas em nove estados brasileiros. Porém, a que apresenta maior distribuição geográfica em território brasileiro é a empresa $\mathbf{A}$, presente em dez estados. Já em termos de atuação internacional, destaca-se a empresa C, presente em mais de sete países.

Das cinco empresas entrevistadas, duas atuam no setor de papel e celulose (B, E), duas no setor da construção civil (C e D) e uma no setor de Gás GLP (A).

Observa-se que as empresas A, C e E, possuem capital fechado, enquanto a empresa D apresenta capital aberto. Já a empresa B possui capital aberto e capital privado pulverizado. Com exceção da empresa A que avaliam sua gestão de forma verticalizada, as demais avaliam sua gestão de forma horizontalizada.

Estrategicamente, os principais benefícios do capital aberto para as empresas são melhorias na gestão, a maior captação de recursos, e o aumento da credibilidade dos stakeholders (DALLA CORTE e PEGORARO 2007).

Na gestão verticalizada, o fato de haver vários níveis gerencias, tende a deixar o processo mais burocrático, mas favorece a coordenação das atividades da empresa. Porém, a gestão horizontalizada se apresenta mais eficiente, pois há redução dos níveis hierárquicos, eliminando trabalhos que não agregam valor ao dar autonomia de decisão aos funcionários sobre suas competências, conferindo maior agilidade nos processos produtivos, além da maior transferência de responsabilidades gerenciais (DALLA CORTE e PEGORARO 2007).

Análise comparativa da matriz dos indicadores da GRI priorizadas pelas empresas pesquisadas

A matriz da GRI versão 3.1, apresenta ao total 84 indicadores para avaliar o desempenho econômico, social e ambiental. É parte do processo de elaboração dos Relatórios de Sustentabilidade, e de responsabilidade da empresa, selecionar os indicadores a serem reportados. A mesma serve para orientar quem utiliza os relatórios das organizações, não sendo obrigatório relatar todos os indicadores sugeridos pela GRI. 
Serão apresentados quais os indicadores constituem a materialidade dos Relatórios de Sustentabilidade das empresas entrevistadas, ou seja, quais não são relatados e quais são destaques em suas publicações. O objetivo é avaliar a aderência das empresas em relação aos indicadores de desempenho socioambiental da GRI.

Para melhor compreensão, os indicadores destacados em azul representam os que são prioridade nas publicações das empresas, já os destacados em cinza representam os indicadores que não são reportados.

O Quadro 6, apresenta os indicadores da matriz de materialidade correspondente a empresa $\mathbf{A}$.

Quadro 6 - Matriz de materialidade empresa A

\begin{tabular}{|c|c|c|c|c|}
\hline \multirow{2}{*}{\multicolumn{2}{|c|}{ Categoria }} & \multirow[t]{2}{*}{ Aspecto } & \multicolumn{2}{|c|}{ Indicadores } \\
\hline & & & Essencial & Adicional \\
\hline \multirow{3}{*}{\multicolumn{2}{|c|}{ Econômica }} & Desempenho econômico & $E C 1, E C 2, E C 3, E C 4$ & N/A \\
\hline & & Presença no mercado & EC6, EC7 & EC5 \\
\hline & & $\begin{array}{l}\text { Impactos econômicos } \\
\text { indiretos }\end{array}$ & EC8 & EC9 \\
\hline \multirow{9}{*}{\multicolumn{2}{|c|}{ Ambiental }} & Materiais & EN1, EN2 & N/A \\
\hline & & Energia & EN3, EN4 & EN5, EN6, EN7 \\
\hline & & Agua & EN8 & EN9, EN10 \\
\hline & & Biodiversidade & EN11, EN12, & $\begin{array}{l}\text { EN13, EN14. } \\
\text { EN15 }\end{array}$ \\
\hline & & $\begin{array}{l}\text { Emissões, Efluentes e } \\
\text { residuos }\end{array}$ & $\begin{array}{l}\text { EN16, EN17, EN19, } \\
\text { EN20, EN21, EN22, } \\
\text { EN23 }\end{array}$ & $\begin{array}{l}\text { EN18, EN24, } \\
\text { EN25 }\end{array}$ \\
\hline & & Produtos e serviços & EN26, EN27 & NIA \\
\hline & & Conformidade & EN28 & N/A \\
\hline & & Transporte & N/A & EN29 \\
\hline & & Geral & N/A & EN30 \\
\hline \multirow{25}{*}{ Social } & \multirow{6}{*}{ Práticas trabalhistas } & Emprego & LA1, LA2, LA3 & LA4 \\
\hline & & Relações trabalhistas & LA5, LA6, & N/A \\
\hline & & $\begin{array}{l}\text { Saúde e segurança no } \\
\text { trabalho }\end{array}$ & LA7, LA8 & LA9, LA10 \\
\hline & & Treinamento e educação & LA11 & LA12, LA13 \\
\hline & & $\begin{array}{c}\text { Diversidade e igualdade de } \\
\text { oportunidades }\end{array}$ & LA14 & NVA \\
\hline & & $\begin{array}{l}\text { Igual remuneração para } \\
\text { mulheres e homens }\end{array}$ & LA15 & NIA \\
\hline & \multirow{9}{*}{ Direitos humanos } & $\begin{array}{l}\text { Práticas de investimentos e } \\
\text { processos de compra }\end{array}$ & HR1, HR2 & HR3 \\
\hline & & Não discriminação & HR4 & N/A \\
\hline & & $\begin{array}{l}\text { Liberdade de associação e } \\
\text { negociação coletiva }\end{array}$ & HR5 & N/A \\
\hline & & Trabalho infantil & HR6 & N/A \\
\hline & & $\begin{array}{c}\text { Trabalho forçado ou análogo } \\
\text { ao escravo }\end{array}$ & HR7 & N/A \\
\hline & & Práticas de segurança & $N / A$ & HR8 \\
\hline & & Direitos indigenas & N/A & HR9 \\
\hline & & Avaliação & HR10 & NIA \\
\hline & & Remediação & HR11 & NVA \\
\hline & \multirow{5}{*}{ Sociedade } & Comunidades locais & SO1 & $\mathrm{SO}, \mathrm{SO} 10$ \\
\hline & & Combate a corrupção & $\mathrm{SO} 2, \mathrm{SO} 3, \mathrm{SO} 4$ & N/A \\
\hline & & Politicas públicas & SO5 & so6 \\
\hline & & Concorrência desleal & N/A & so7 \\
\hline & & Conformidade & SO8, & N/A \\
\hline & \multirow{5}{*}{$\begin{array}{l}\text { Responsabilidade } \\
\text { pelo produto }\end{array}$} & Saúde e segurança do cliente & PR1 & PR2 \\
\hline & & $\begin{array}{c}\text { Rotulagem de produtos e } \\
\text { serviços }\end{array}$ & PR3 & PR4, PR5 \\
\hline & & Comunicação de marketing & PR6 & PR7 \\
\hline & & Privacidade do cliente & N/A & PR8 \\
\hline & & Conformidade & PR9 & N/A \\
\hline
\end{tabular}

Fonte: Autores, 2016. 
No Quadro 6, observa-se que: quanto aos indicadores socioambientais, a empresa $\mathbf{A}$ reporta 90\% (76 de 84) dos indicadores sugeridos pela GRI para avaliação do seu desempenho socioambiental, reflexo da experiência da empresa em publicar seus resultados. Segundo o respondente, os relatórios são fundamentais para a expansão de mercado, motivo pelo qual a empresa preza em relatar o máximo de indicadores possíveis. A Figura 3 ilustra o percentual de cada categoria.

Figura 3 - Aderência dos indicadores socioambientais empresa $\mathbf{A}$

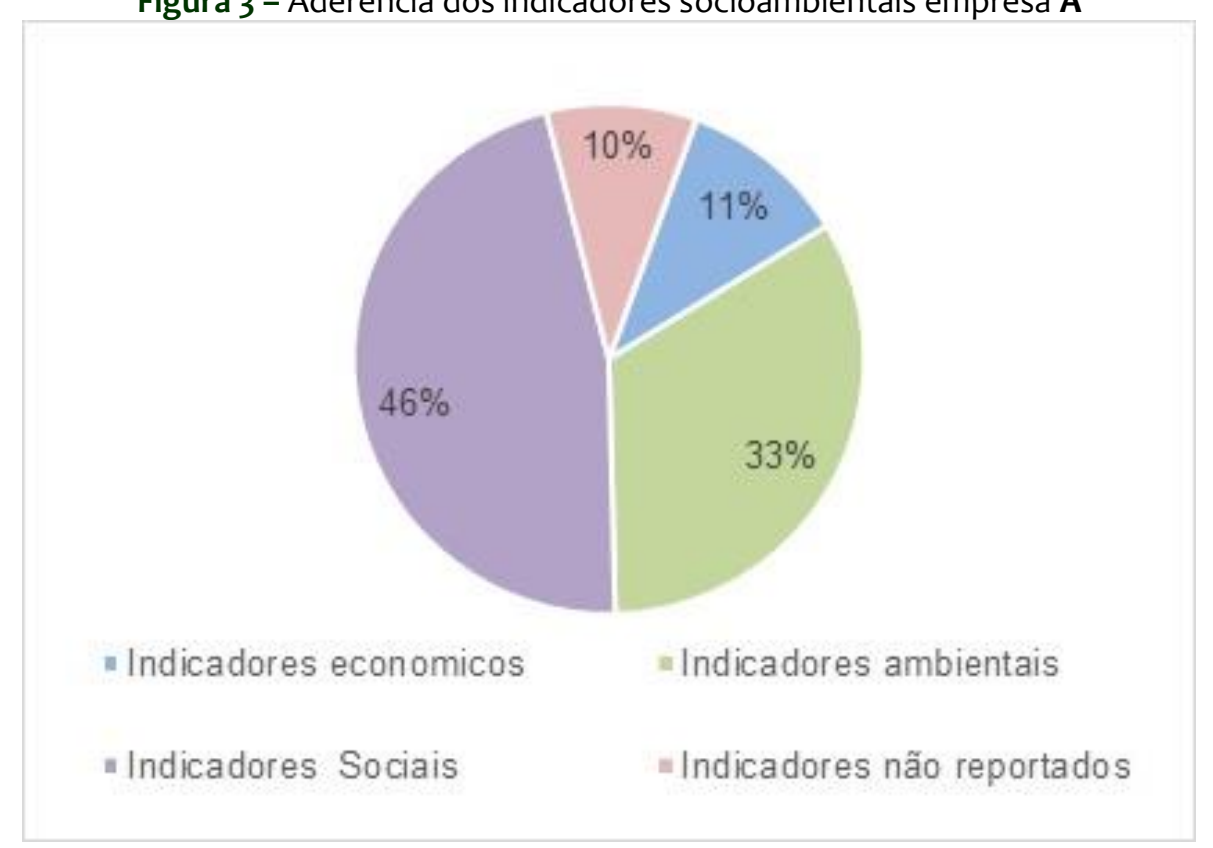

Fonte: Autores, 2016

Conclui-se que em relação aos indicadores econômicos, todos da categoria são reportados e sete deles considerados prioridade. No desempenho ambiental apenas dois não são relatados, sendo 18 prioridades nas publicações.

Observou-se que os indicadores sociais representam 46\% (39 de 84), mesmo sendo considerados apenas dois indicadores desta categoria como prioridade na entrevista.

No Quadro 7, são apresentados os indicadores da matriz de materialidade correspondente a empresa $\mathbf{B}$. 
Quadro 7 - Matriz de materialidade empresa B

\begin{tabular}{|c|c|c|c|c|}
\hline \multirow{2}{*}{\multicolumn{2}{|c|}{ Categoria }} & \multirow[t]{2}{*}{ Aspecto } & \multicolumn{2}{|c|}{ Indicadores } \\
\hline & & & \begin{tabular}{|c|} 
Essencial \\
\end{tabular} & Adicional \\
\hline \multirow{3}{*}{\multicolumn{2}{|c|}{ Econômica }} & Desempenho econômico & $\begin{array}{l}\text { EC1, EC2, EC3, } \\
\text { EC4 }\end{array}$ & N/A \\
\hline & & Presença no mercado & EC6, EC7 & EC5 \\
\hline & & Impactos econômicos indiretos & EC8 & EC9 \\
\hline \multirow{9}{*}{\multicolumn{2}{|c|}{ Ambiental }} & Materiais & EN1, EN2 & N/A \\
\hline & & Energia & EN3, EN4 & EN5, EN6, EN7 \\
\hline & & Agua & EN8 & EN9, EN10 \\
\hline & & Biodiversidade & EN11, EN12, & $\begin{array}{l}\text { EN13, EN14. } \\
\text { EN15 }\end{array}$ \\
\hline & & Emissões, Efluentes e resíduos & $\begin{array}{l}\text { EN16, EN17, EN19, } \\
\text { EN20, EN21, EN22, } \\
\text { EN23 }\end{array}$ & $\begin{array}{l}\text { EN18, EN24, } \\
\text { EN25 }\end{array}$ \\
\hline & & Produtos e serviços & EN26, EN27 & NVA \\
\hline & & Conformidade & EN28 & N/A \\
\hline & & Transporte & N/A & EN29 \\
\hline & & Geral & N/A & EN30 \\
\hline \multirow{25}{*}{ Social } & \multirow{6}{*}{ Práticas trabalhistas } & Emprego & LA1, LA2, LA3 & LA4 \\
\hline & & Relações trabalhistas & LA5, LA6, & N/A \\
\hline & & Saúde e segurança no trabalho & LA7, LA8 & LA9, LA10 \\
\hline & & Treinamento e educação & LA11 & LA12, LA13 \\
\hline & & $\begin{array}{c}\text { Diversidade e igualdade de } \\
\text { oportunidades }\end{array}$ & LA14 & N/A \\
\hline & & $\begin{array}{c}\text { Igual remuneração para } \\
\text { mulheres e homens }\end{array}$ & LA15 & $\mathrm{N} / \mathrm{A}$ \\
\hline & \multirow{9}{*}{ Direitos humanos } & $\begin{array}{l}\text { Práticas de investimentos e } \\
\text { processos de compra }\end{array}$ & HR1, HR2 & HR3 \\
\hline & & Não discriminação & HR4 & $\mathrm{N} / \mathrm{A}$ \\
\hline & & $\begin{array}{l}\text { Liberdade de associação e } \\
\text { negociação coletiva }\end{array}$ & HR5 & $\mathrm{N} / \mathrm{A}$ \\
\hline & & Trabalho infantil & HR6 & N/A \\
\hline & & $\begin{array}{l}\text { Trabalho forçado ou análogo ao } \\
\text { escravo }\end{array}$ & HR7 & $\mathrm{N} / \mathrm{A}$ \\
\hline & & Práticas de segurança & $\mathrm{N} / \mathrm{A}$ & HR8 \\
\hline & & Direitos indigenas & $\mathrm{N} / \mathrm{A}$ & HR9 \\
\hline & & Avaliação & HR10 & N/A \\
\hline & & Remediação & HR11 & $\mathrm{N} / \mathrm{A}$ \\
\hline & \multirow{5}{*}{ Sociedade } & Comunidades locais & SO1 & SO9, SO10 \\
\hline & & Combate a corrupção & $\mathrm{SO} 2, \mathrm{SO} 3, \mathrm{SO} 4$ & N/A \\
\hline & & Políticas públicas & SO5 & SO6 \\
\hline & & Concorrência desleal & $\mathrm{N} / \mathrm{A}$ & SO7 \\
\hline & & Conformidade & $\mathrm{SO} 8$ & N/A \\
\hline & \multirow{5}{*}{$\begin{array}{l}\text { Responsabilidade } \\
\text { pelo produto }\end{array}$} & Saúde e segurança do cliente & PR1 & PR2 \\
\hline & & $\begin{array}{c}\text { Rotulagem de produtos e } \\
\text { serviços }\end{array}$ & PR3 & PR4, PR5 \\
\hline & & Comunicação de marketing & PR6 & PR7 \\
\hline & & Privacidade do cliente & N/A & PR8 \\
\hline & & Conformidade & PR9 & N/A \\
\hline
\end{tabular}

Fonte: Autores, 2016. 
Ao analisar o Quadro 7, verificou-se que a empresa B, tem uma aderência de 73\% (61 de 84 ) dos indicadores sugeridos pela GRI, e que 27\% (23 de 84) dos indicadores não estão incluídos na matriz de materialidade da empresa. A Figura 4 ilustra o percentual de cada categoria.

Figura 4 - Aderência dos indicadores socioambientais empresa B

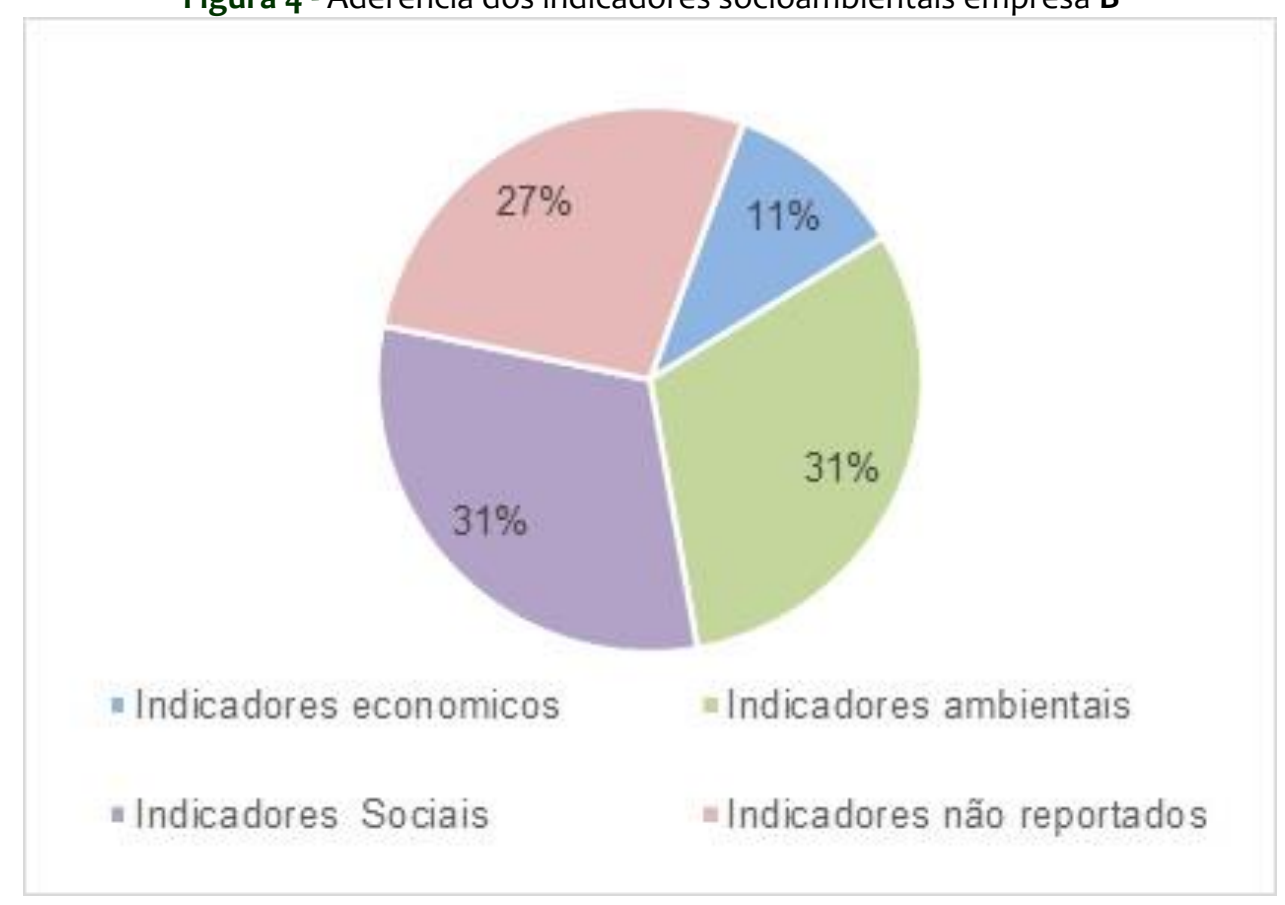

Fonte: Autores, 2016.

Conforme o Figura 4, podemos inferir que a empresa B apresenta equilíbrio na aderência entre nas três categorias. Porém, ao confrontar-se os dados da pesquisa com o Relatório de Sustentabilidade, verificou-se que os indicadores de desempenho econômico e ambiental, não tem o destaque mencionado pelo respondente na entrevista.

Já os indicadores de "Comunidade locais", apresentam maior destaque, fica evidente a preocupação da empresa em inserir a comunidade local, colaboradores e suas famílias em programas de educação e cultura desenvolvidos pela empresa.

No próximo Quadro 8, será apresentado os indicadores socioambientais referente a materialidade da empresa $\mathbf{C}$. 
Quadro 8 - Matriz de materialidade empresa C

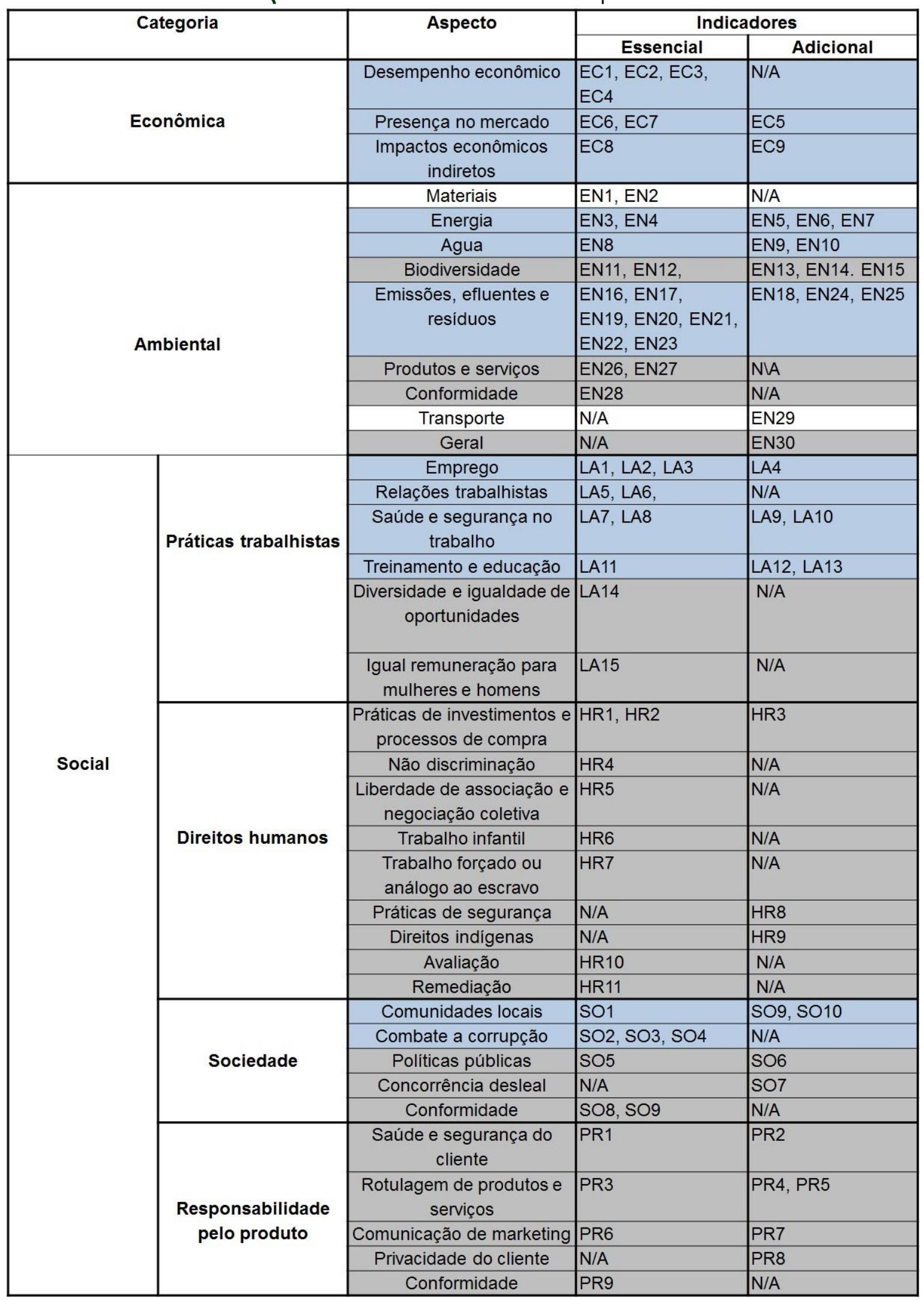

Fonte: Autores, 2016 
Ao analisar os indicadores da matriz de materialidade do Relatório de Sustentabilidade da empresa $\mathbf{C}$, verificou-se que a mesma reporta apenas os indicadores, considerados prioridade pelo respondente nas suas publicações, ou seja apenas $57 \%$ (48 de 84) deles foram reportados no último relatório.

A Figura 5, ilustra a aderência dos indicadores socioambiental da GRI, separado por categorias.

Figura 5 - Aderência de indicadores socioambientais empresa C

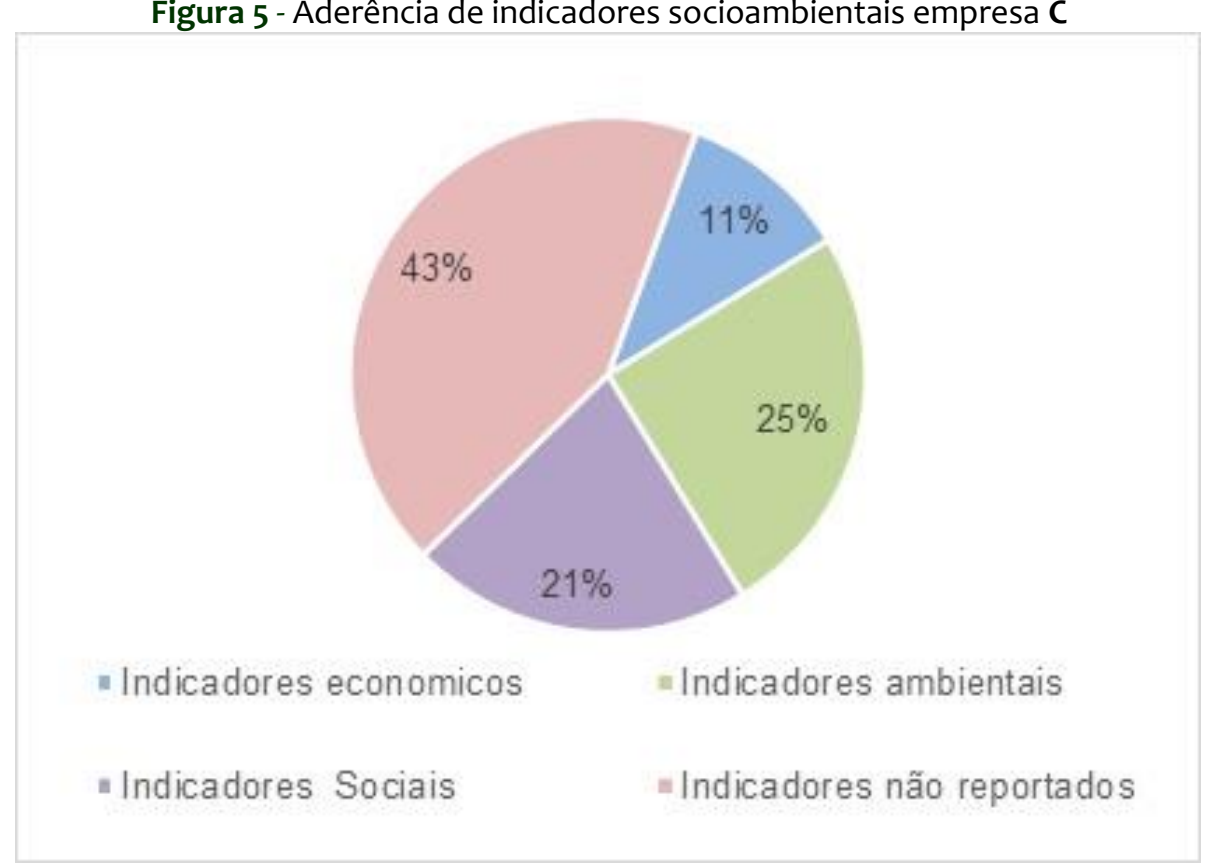

Fonte: Autores, 2016

Conforme o Figura 5, percebe-se que a empresa C não reporta 43\% (36 de 84) dos indicadores de desempenho sugeridos pela matriz GRI, é importante lembrar, que em 2014 foi o primeiro ano em que a empresa passou a divulgar seu desempenho socioambiental. Segundo o respondente, já está programado para a próxima publicação uma maior abrangência dos indicadores, porém, não está definido se a empresa continuará a usar a versão $\mathrm{G}_{3.1}$, ou se vai aderir a última geração (G4).

O Quadro 9 corresponde a matriz de materialidade da empresa D. 
Quadro 9 - Matriz de materialidade empresa D

\begin{tabular}{|c|c|c|c|c|}
\hline \multirow{2}{*}{\multicolumn{2}{|c|}{ Categoria }} & \multirow[t]{2}{*}{ Aspecto } & \multicolumn{2}{|c|}{$\begin{array}{l}\text { Indicadores } \\
\end{array}$} \\
\hline & & & Essencial & Adicional \\
\hline \multirow{3}{*}{\multicolumn{2}{|c|}{ Econômica }} & Desempenho econômico & $\begin{array}{l}\text { EC1, EC2, EC3, } \\
\text { EC4 }\end{array}$ & $\mathrm{N} / \mathrm{A}$ \\
\hline & & Presença no mercado & EC6, EC7 & EC5 \\
\hline & & $\begin{array}{l}\text { Impactos econômicos } \\
\text { indiretos }\end{array}$ & EC8 & EC9 \\
\hline \multirow{9}{*}{\multicolumn{2}{|c|}{ Ambiental }} & Materiais & EN1, EN2 & N/A \\
\hline & & Energia & EN3, EN4 & EN5, EN6, EN7 \\
\hline & & Agua & EN8 & EN9, EN10 \\
\hline & & Biodiversidade & EN11, EN12, & EN13, EN14. EN15 \\
\hline & & $\begin{array}{l}\text { Emissões, efluentes e } \\
\text { resíduos }\end{array}$ & $\begin{array}{l}\text { EN16, EN17, } \\
\text { EN19, EN20, EN21, } \\
\text { EN22, EN23 }\end{array}$ & EN18, EN24, EN25 \\
\hline & & Produtos e serviços & EN26, EN27 & NIA \\
\hline & & Conformidade & EN28 & N/A \\
\hline & & Transporte & N/A & EN29 \\
\hline & & Geral & N/A & EN30 \\
\hline \multirow{6}{*}{\multicolumn{2}{|c|}{$\begin{array}{l}\text { Práticas } \\
\text { trabalhistas }\end{array}$}} & Emprego & LA1, LA2, LA3 & LA4 \\
\hline & & Relações trabalhistas & LA5, LA6, & N/A \\
\hline & & $\begin{array}{c}\text { Saúde e segurança no } \\
\text { trabalho }\end{array}$ & LA7, LA8 & LA9, LA10 \\
\hline & & Treinamento e educação & LA11 & LA12, LA13 \\
\hline & & $\begin{array}{c}\text { Diversidade e igualdade de } \\
\text { oportunidades }\end{array}$ & LA14 & $\mathrm{N} / \mathrm{A}$ \\
\hline & & $\begin{array}{c}\text { Igual remuneração para } \\
\text { mulheres e homens }\end{array}$ & LA15 & $\mathrm{N} / \mathrm{A}$ \\
\hline \multirow{19}{*}{ Social } & \multirow{9}{*}{ Direitos humanos } & $\begin{array}{c}\text { Práticas de investimentos e } \\
\text { processos de compra }\end{array}$ & HR1, HR2 & HR3 \\
\hline & & Não discriminação & HR4 & N/A \\
\hline & & $\begin{array}{c}\text { Liberdade de associação e } \\
\text { negociação coletiva }\end{array}$ & HR5 & $\mathrm{N} / \mathrm{A}$ \\
\hline & & Trabalho infantil & HR6 & N/A \\
\hline & & $\begin{array}{c}\text { Trabalho forçado ou análogo } \\
\text { ao escravo }\end{array}$ & HR7 & $\mathrm{N} / \mathrm{A}$ \\
\hline & & Práticas de segurança & N/A & HR8 \\
\hline & & Direitos indigenas & N/A & HR9 \\
\hline & & Avaliação & HR10 & N/A \\
\hline & & Remediação & HR11 & N/A \\
\hline & \multirow{5}{*}{ Sociedade } & Comunidades locais & SO1 & SO9, SO10 \\
\hline & & Combate a corrupção & $\mathrm{SO} 2, \mathrm{SO} 3, \mathrm{SO} 4$ & N/A \\
\hline & & Políticas públicas & SO5 & SO6 \\
\hline & & Concorrência desleal & $\mathrm{N} / \mathrm{A}$ & SO7 \\
\hline & & Conformidade & 508 & N/A \\
\hline & \multirow{5}{*}{$\begin{array}{l}\text { Responsabilidade } \\
\text { pelo produto }\end{array}$} & $\begin{array}{c}\text { Saúde e segurança do } \\
\text { cliente }\end{array}$ & PR1 & PR2 \\
\hline & & $\begin{array}{l}\text { Rotulagem de produtos e } \\
\text { serviços }\end{array}$ & PR3 & PR4, PR5 \\
\hline & & Comunicação de marketing & PR6 & PR7 \\
\hline & & Privacidade do cliente & N/A & PR8 \\
\hline & & Conformidade & PR9 & N/A \\
\hline
\end{tabular}

Fonte: Autores, 2016 
A aderência da empresa $\mathbf{D}$ em relação aos indicadores da GRI é de $87 \%$ (73 de 84 ) e apenas oito indicadores não foram reportados pela empresa. Segundo o respondente, para a próxima publicação a expectativa é que se adote a quarta geração de diretrizes da matriz. Essa quarta gerção incluí a questão de igualdade de gênero e indicadores que reportam como acontece o relacionamento contínuo com os stakeholders, o que vai otimizar a abrangência do relatório. Na Figura 6, é possível analisar a aderência da empresa em cada aspecto, econômico, ambiental e social.

Figura 6 - Aderência de indicadores socioambientais empresa D

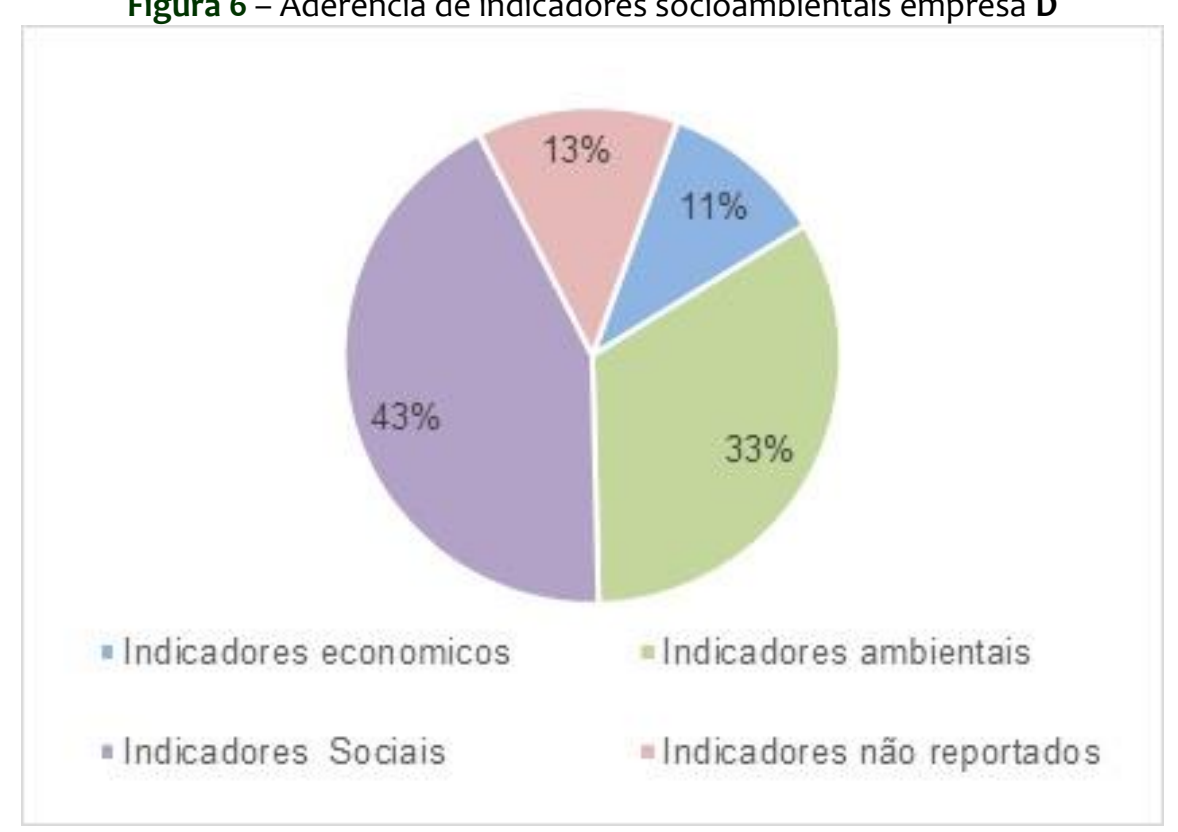

Fonte: Autores, 2016

Como na empresa $\mathbf{A}$, pode-se inferir que apesar da empresa $\mathbf{D}$, mesmo destacando apenas um indicador social, a mesma tem um empenho significativo em melhorar a cultura da organização para o desenvolvimento sustentável.

O entrevistado, destacou os benefícios em economia para a empresa, quanto ao consumo de energia e agua, a redução nesses custos foi significativa financeiramente.

Por fim, o Quadro 10 a matriz de materialidade utilizada pela empresa E. 
Quadro 10 - Matriz de materialidade utilizada empresa E

\begin{tabular}{|c|c|c|c|c|}
\hline \multirow{2}{*}{\multicolumn{2}{|c|}{ Categoria }} & \multirow[t]{2}{*}{ Aspecto } & \multicolumn{2}{|c|}{ Indicadores } \\
\hline & & & Essencial & Adicional \\
\hline \multirow{3}{*}{\multicolumn{2}{|c|}{ Econômica }} & Desempenho econômico & EC1, EC2, EC3, EC4 & N/A \\
\hline & & Presença no mercado & EC6, EC7 & EC5 \\
\hline & & Impactos econômicos indiretos & EC8 & EC9 \\
\hline \multirow{9}{*}{\multicolumn{2}{|c|}{ Ambiental }} & Materiais & EN1, EN2 & $\mathrm{N} / \mathrm{A}$ \\
\hline & & Energia & EN3, EN4 & EN5, EN6, EN7 \\
\hline & & Agua & EN8 & EN9, EN10 \\
\hline & & Biodiversidade & EN11, EN12, & EN13, EN14. EN15 \\
\hline & & Emissões, Efluentes e resíduos & $\begin{array}{l}\text { EN16, EN17, EN19, } \\
\text { EN20, EN21, EN22, } \\
\text { EN23 }\end{array}$ & EN18, EN24, EN25 \\
\hline & & Produtos e serviços & EN26, EN27 & NIA \\
\hline & & Conformidade & EN28 & N/A \\
\hline & & Transporte & N/A & EN29 \\
\hline & & Geral & N/A & EN30 \\
\hline \multirow{25}{*}{ Social } & \multirow{6}{*}{$\begin{array}{l}\text { Práticas } \\
\text { trabalhistas }\end{array}$} & Emprego & LA1, LA2, LA3 & LA4 \\
\hline & & Relações trabalhistas & LA5, LA6, & N/A \\
\hline & & Saúde e segurança no trabalho & LA7, LA8 & LA9, LA10 \\
\hline & & Treinamento e educação & LA11 & LA12, LA13 \\
\hline & & $\begin{array}{l}\text { Diversidade e igualdade de } \\
\text { oportunidades }\end{array}$ & LA14 & N/A \\
\hline & & $\begin{array}{c}\text { Igual remuneração para } \\
\text { mulheres e homens }\end{array}$ & LA15 & N/A \\
\hline & \multirow{9}{*}{ Direitos humanos } & $\begin{array}{c}\text { Práticas de investimentos e } \\
\text { processos de compra }\end{array}$ & HR1, HR2 & HR3 \\
\hline & & Não discriminação & HR4 & N/A \\
\hline & & $\begin{array}{l}\text { Liberdade de associação e } \\
\text { negociação coletiva }\end{array}$ & HR5 & $\mathrm{N} / \mathrm{A}$ \\
\hline & & \begin{tabular}{|c|} 
Trabalho infantil \\
\end{tabular} & HR6 & N/A \\
\hline & & $\begin{array}{c}\text { Trabalho forçado ou análogo ao } \\
\text { escravo }\end{array}$ & HR7 & N/A \\
\hline & & Práticas de segurança & N/A & HR8 \\
\hline & & Direitos indigenas & N/A & HR9 \\
\hline & & Avaliação & HR10 & N/A \\
\hline & & Remediação & HR11 & N/A \\
\hline & \multirow{5}{*}{ Sociedade } & Comunidades locais & $\mathrm{SO}$ & SO10 \\
\hline & & Combate a corrupção & $\mathrm{SO} 2, \mathrm{SO} 3, \mathrm{SO} 4$ & N/A \\
\hline & & Políticas públicas & SO5 & SO6 \\
\hline & & Concorrência desleal & N/A & SO7 \\
\hline & & Conformidade & SO8, & $\mathrm{N} / \mathrm{A}$ \\
\hline & \multirow{5}{*}{$\begin{array}{l}\text { Responsabilidade } \\
\text { pelo produto }\end{array}$} & Saúde e segurança do cliente & PR1 & PR2 \\
\hline & & $\begin{array}{c}\text { Rotulagem de produtos e } \\
\text { serviços }\end{array}$ & PR3 & PR4, PR5 \\
\hline & & Comunicação de marketing & PR6 & PR7 \\
\hline & & Privacidade do cliente & $\mathrm{N} / \mathrm{A}$ & PR8 \\
\hline & & Conformidade & PR9 & N/A \\
\hline
\end{tabular}

Fonte: Autores, 2016

Embora seja o primeiro ano que a empresa E publica seu desempenho socioambiental, a mesma abrange 74\% (62 de 84) dos indicadores sugeridos e prevê para o próximo relatório adotar a versão G4 das diretrizes GRI. 
A Figura 7, apresenta a porcentagem de aderência por categoria.

Figura 7 - Aderência de indicadores socioambientais empresa E

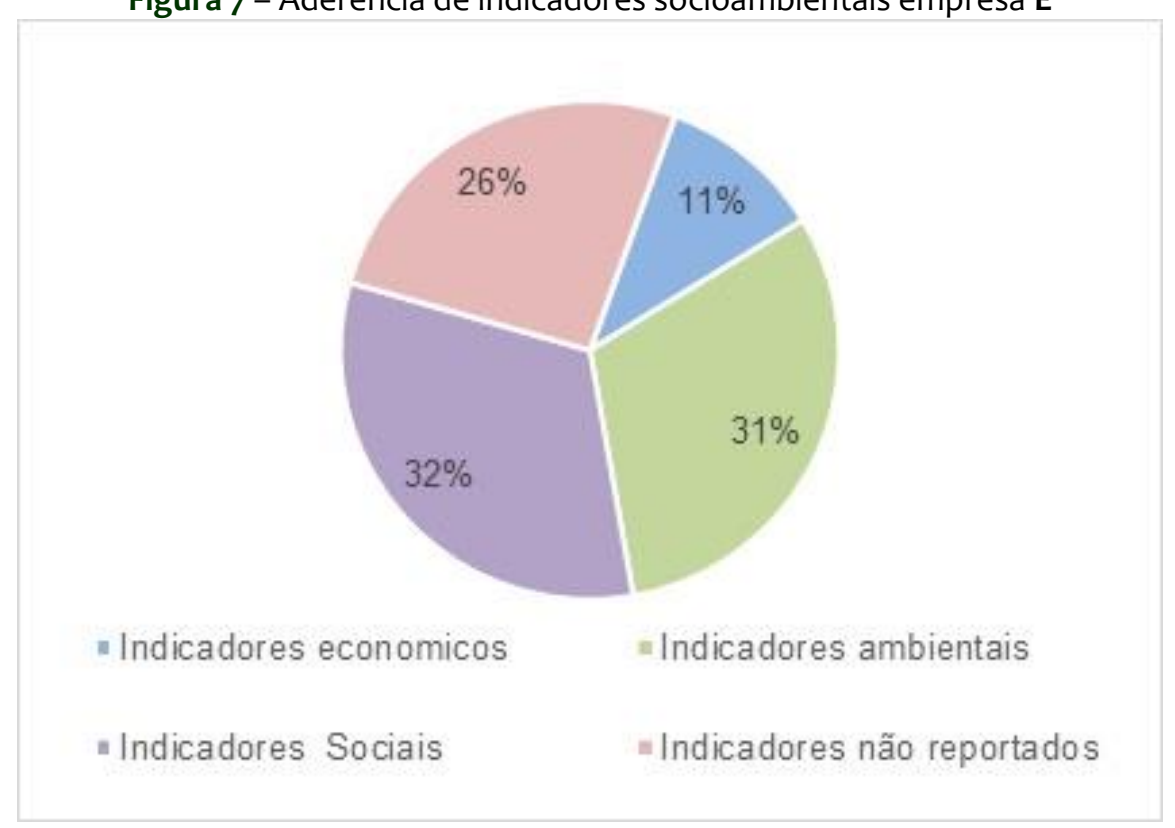

Fonte: Autores, 2016

Mesmo a empresa priorizando apenas dois indicativos sociais, a partir da entrevista, concluiu-se que a mesma apresenta um número significativo de projetos sociais com foco na comunidade ao entorno. Sempre buscando manter um vínculo com a comunidade local.

Segundo o respondente apesar da empresa não possuir política específica para inclusão da comunidade local nos processos produtivos, há um grande incentivo para valorizar a região. Apesar de já ter passado por mais de três transações de venda, a grande maioria de colaboradores continuam a trabalhar na empresa. A exemplo, o respondente, que faz parte da direção de comunicação externa e está há vinte anos na empresa, relatou a baixa rotatividade dos colaboradores.

No Quadro 11 é possível visualizar a aderência das empresas em cada aspecto, econômico, ambiental e social.

\begin{tabular}{|c|c|c|c|}
\multicolumn{4}{|c|}{ Quadro 11 - Porcentagem de aderência dos indicadores GRI por categoria } \\
\hline Empresa & $\begin{array}{c}\text { Indicadores } \\
\text { Econômicos }\end{array}$ & $\begin{array}{c}\text { Indicadores } \\
\text { Ambientais }\end{array}$ & $\begin{array}{c}\text { Indicadores } \\
\text { Sociais }\end{array}$ \\
\hline A & $100 \%(9 / 9)$ & $93 \%(28 / 30)$ & $87 \%(39 / 45)$ \\
\hline B & $100 \%(9 / 9)$ & $87 \%(26 / 30)$ & $58 \%(26 / 45)$ \\
\hline C & $100 \%(9 / 9)$ & $70 \%(21 / 30)$ & $40 \%(18 / 45)$ \\
\hline D & $100 \%(9 / 9)$ & $93 \%(28 / 30)$ & $80 \%(36 / 45)$ \\
\hline E & $100 \%(9 / 9)$ & $87 \%(26 / 30)$ & $60 \%(27 / 45)$ \\
\hline
\end{tabular}

Fonte: Autores, 2016 


\section{CONSIDERAÇÕES FINAIS}

O estudo evidencia que é significativa a preocupação das empresas com o desenvolvimento sustentável. Todas as organizações estudadas apresentavam práticas de sustentabilidade antes mesmo de iniciarem a divulgação do seu desempenho socioambiental.

As empresas A, B e D, publicam o Relatório de Sustentabilidade da GRI, desde 2004, enquanto as empresas C e E publicaram pela primeira vez em 2014.

Todas as empresas contam com um Comitê de Sustentabilidade, que auxilia no mapeamento e elaboração das ações socioambientais, além de auxiliarem na elaboração dos relatórios, exceto a empresa $\mathbf{A}$, que conta com ajuda de uma assessoria terceirizada.

Em relação a aderência das diretrizes GRI, percebe-se que as empresas A e D apresentam maior percentual, reportando respectivamente $90 \%$ e $87 \%$ dos indicadores sugeridos pela matriz GRI. Igualmente, apresentam o menor percentual de não conformidade. Reflexo da experiência em relatar suas ações.

As empresas B e E apresentam um percentual inferior, porém ainda significativo, reportando mais de $70 \%$.

A empresa C, reporta apenas 57\% dos indicadores, porém, é o primeiro ano da publicação. Todas as empresas relataram que para a próxima publicação a expectativa é o aumento da abrangência.

Todas as empresas reportam 100\% dos indicadores de desempenho econômico, indicando que apresentam mais credibilidade perante os stakeholders.

Os indicadores ambientais são significativamente reportados por todas as empresas, porém, os aspectos energia, agua, transporte, emissões, efluentes e resíduos são considerados pelas empresas os mais importantes. Segundo os respondentes, esses aspectos refletem vantagens financeiras, pois o monitoramento auxilia na diminuição dos gastos.

A porcentagem dos indicares sociais, variam entre as empresas, pois, aspectos como setor de atuação, porte, localização entre outros, refletem diretamente na elaboração da matriz de materialidade. Todas indicaram como prioridade os aspectos sociais treinamento e educação e combate a corrupção. 
A partir dos resultados foi possível avaliar, quanto ao nível de aderência, que as empresas da pesquisa divulgam mais intensamente os indicadores econômicos, seguidos dos ambientais e sociais. A literatura defende que as empresas divulgam um maior nível de informações voluntárias quando essas podem gerar benefícios para as empresas. Além de constatar-se que as empresas estão, cada vez mais, prestando informações para a comunidade.

A pesquisa possibilitou visualizar a importância das diretrizes da Global Reporting Initiative para avaliação de indicadores de sustentabilidade, pois permite visualizar problemas que se repetem, auxiliando o gerenciamento de riscos nas operações e apoiam a comunicação fortalecendo o diálogo e a confiança das partes interessadas. O reconhecimento da marca foi indicado como maior incentivo a aderência das publicações.

\section{REFERÊNCIAS BIBLIOGRÁFICAS}

ALMEIDA, F. A. Desenvolvimento sustentável 2012-2050: visão, rumos e contradições. Rio de Janeiro: Elsevier, 2012.

BOFF, L. Sustentabilidade: o que é: o que não é. Petrópolis, RJ: Vozes, 2012.

CATIZZONE, M. Desenvolvimento sustentável: um conceito que precisa se tornar operacional. In: ROMEIRO, A. (org). Avaliação e contabilização de impactos ambientais. Campinas, SP: Editora da UNICAMP, 2004. p. 216-229.

DALLA CORTE, T.; PEGORARO, P. R. Abertura de Capital, Benefícios e Retraíeis. In: Revistas UTFPR, Pato Branco. 2007.

GRI - Global Reporting Initiative. Diretrizes para Relatório de Sustentabilidade de GRI - 2011. Disponível em: https://www.globalreporting.org/Pages/default.aspx

LEFF,

En. Espacio,lugar

y tiempo: la reapropiación socia Ide la naturaleza y la construcción local de la racionalidad ambiental. In: Desenvolvimento e Meio Ambiente - Teoria e Metodologia em Meio Ambiente e Desenvolvimento. Curitiba: Editora da UFPR, n 1, 2000. p. 57-70.

MALHOTRA, N. K. Pesquisa de Marketing: uma orientação aplicada. 3. ed. Porto Alegre: Bookman, 2001. p. 720.

MONEVA, JM.; ARCHEL, P.; CORREA, C. GRI and the camouflaging of corporate unsustainability. In: Accounting forum. Elsevier, 2006. p. 121-137. 
OLIVEIRA, M. D. A. S., CAMPOS, L. M. D. S., SEHNEM, S., ROSSETTO, A. M. (2013). Relatórios de sustentabilidade segundo a Global Reporting Initiative (GRI): uma análise de correspondências entre os setores econômicos brasileiros. v. 23, n. 4, p. 55-70, 2013.

QUELHAS, O. L. G. et al. Motivadores mercadológicos para o desempenho ambiental. In: ADISSI, Paulo et al. Gestão ambiental de unidades produtivas. Elsevier Brasil, 2013

ROCHA, JM. Sustentabilidade e Desenvolvimento Noções e Interpretações. In: Sustentabilidade em questão: Economia, sociedade e meio ambiente. Jundiaí: Paco Editorial, 2011. p 12-38.

SAVITZ, A. W.; WEBER, K. A empresa sustentável: o verdadeiro sucesso é o lucro com responsabilidade social e ambiental. Rio de Janeiro: Elsevier, 2007.

VEIGA, JE. Desenvolvimento Sustentável: o desafio do século XXI. Rio de Janeiro: Garamond, 2005. 